\title{
A Community with a Shared Future for Mankind and Problems and Countermeasures of China-EU Cooperation
}

\author{
Yanjun Dai \\ School of Marxism \\ Dalian University of Technology \\ Dalian, China
}

\author{
Jiachi Wang \\ School of Marxism \\ Dalian University of Technology \\ Dalian, China
}

\begin{abstract}
Since the 18th Communist Party of China National Congress, President Xi Jinping has delivered many speeches on a community with a shared future for mankind, expressing Chinese vision on how to promote world's development. The Belt and Road Initiative is a project of the century to build a community with a shared future for mankind. The cooperation between China and Europe plays an important role in building a community with a shared future and the Belt and Road Initiative. Under the view of a community with a shared future, this article presents an introduction to the background and the significance of ChinaEU cooperation. Based on it, this article aims to analyze what will hinder China-EU cooperation and how to overcome the obstacles.
\end{abstract}

Keywords-a community with a shared future for mankind; The Belt and Road Initiative; China-EU cooperation

\section{INTRODUCTION}

The report of the 18th Communist Party of China National Congress pointed out:" In promoting mutually beneficial cooperation, we should raise awareness about human beings sharing a community of common destiny. A country should accommodate the legitimate concerns of others when pursuing its own interests; and it should promote common development of all countries when advancing its own development. Countries should establish a new type of global development partnership that is more equitable and balanced, stick together in times of difficulty, both share rights and shoulder obligations, and boost the common interests of mankind." It can be said that the idea a community with a shared future for mankind is the main theoretical basis for Chinese government's foreign policy in the new era. How to build a community with a shared future for mankind which benefits the economic and social development of the whole world, and pushes the civilization and progress of all mankind, the Party and People's government, at the core of General Secretary Xi Jinping, have given the "China answer" - the Belt and Road Initiative. As the main diplomatic strategy in the new era of China, the Belt and Road Initiative has laid a solid foundation for building a community with a shared future for mankind through deep communication and cooperation with participating countries. China-EU cooperation, as a core content of the Belt and Road Initiative, is a most relevant one with its problems and corresponding solutions worth pondering.

\section{THE CONCEPT OF A COMMUNITY WITH A SHARED FUTURE FOR MANKIND}

A community with a shared future for mankind means, that a country should accommodate the legitimate concerns of others when pursuing its own interests; and it should promote common development of all countries when advancing its own development. Through exchange and cooperation, all the countries around the world make efforts for the common benefits, and shoulder the common responsibilities, finally realizing the common liberation and progress of all mankind. There is only one earth and we live in one world, therefore, we must call for the awareness of global community of a shared future.

First of all, we should foster a new type of international relations in the new era. Since ancient times, countries often resort to war to solve disputes. Even in recent 100 years, there have been two World Wars. Wars and armed confrontation have brought tremendous suffering to all mankind. With the development of science, the destructive power of modern weapons is no longer the same. Nuclear wars can even bring about global disasters. Under this background, to foster a new type of international relations becomes a core issue of the community of shared future consciousness. With the rapid development of information technology and economic globalization in the 21 st century, countries are more interdependent than ever. More and more countries realize that communication and cooperation can promote regional stability and economic development other than disputes and confrontation. Power disputes between countries can be diluted by dialogue and exchange in an international order. All countries can maintain and protect interdependent relationships through international systems, mechanisms and organizations, thus providing an open platform for common development and common interests of all countries, which is the prerequisite of a community with a shared future for mankind. 
Second, we call for constructing the thinking of common interests. Traditional national interest thinking is narrow and extremely self-interested. Under the guidance of this, countries have no trust in each other and prefer to set up trade barriers to protect their own interest. Obviously, this has seriously hindered the development of global economy and also exacerbated the polarization in economy between countries, which is extremely passive and unfair to developing countries. In recent years, economic globalization has prompted people to rethink the traditional view of national interests. It is the choice for each country between their own interests or common development. The thinking of common interests help mankind break the bottleneck of greed and conservatism. Countries leverage their respective strengths through cooperation, thus producing a multiplying effect. This will not only promote the development of the developing countries, but also make the developed countries get rid of the shadow of economic crisis, and find new economic growth point. All the countries in the world are on the same boat. There is no doubt that all the countries gradually have the common interests, which is an important part of a community with a shared future for mankind.

Third, cultural communication around the world is another core connotation. Different countries, civilizations, languages and historical cultures make up the human civilization on the earth. The development of human civilization cannot be separated from cultural exchanges. The ancient Chinese invented gunpowder and compass, which spread to the western countries to promote the development of weapons and navigation; the western Marxism thought spread to China, which has produced the socialist theories with Chinese characteristics and guided the correct direction of the great goal of national rejuvenation. At present, under the condition that the Internet connects all countries in an unprecedented way, only the full sharing and exchange of civilizations can reduce disputes, accelerate the progress of world civilization, and provide internal motivation for the construction of a community with a shared future for mankind.

At last, environmental protection and sustainable development are also core connotation. Since the industrial revolution, human beings have highly exploited and utilized natural resources and thus bringing about environmental pollution and resource consumption, which has caused great disasters to mankind. This is the problem that all mankind needs to face together_living in a blue sky, living in a global village, no matter which country produces pollution, consumes resources, will damage ecological environment of all mankind. Therefore, we call for protecting environment as the same as a community with a shared future for mankind.

\section{The BACKGround AND MEANING OF CHINA-EU COOPERATION}

Compared with other state-to-state relations, China-EU relation is special. Both China and Europe have splendid and glorious civilization and history. China is the birthplace of oriental civilization, while Europe is the birthplace of western civilization, so there are a lot of similarities and differences in culture. Both China and Europe have a vast continent and a large population, and have very important position in the world. Actually, there is no direct sovereignty, territorial, or geopolitical dispute between China and Europe, and there have been no direct conflicts between China and European countries since World War II. Obviously, there is nearly no direct contradiction between China and Europe. On the contrary, they have large scope of cooperation, such as culture, sports, education and technology. Therefore, exchanges and cooperation should be the central theme in China-EU relation.

During the long history, China has had a lot of cooperation and exchange with Europe. In the Han Dynasty, Chinese silk was transported to Europe through the Silk Road. Julius Caesar of Rome had been wearing Chinese silk robes to see a play, causing a sensation. At that time, Chinese silk became a luxury for Roman courts and nobles. They called China as Seres. In the Yuan Dynasty, <The Travels of Marco Polo $>$ has aroused Europeans' great curiosity about China. By introducing the Chinese Confucianism, Chinese history, geography and social system, as well as astronomy, medicine, zoology, botany and literature, the Jesuit missionaries' in 15th and 16th century caused the "Chinese culture craze" in Europe for a century. At that time, Europe advocated China's silk, spices, tea, lacquer ware, porcelain, and absorbed China's material civilization. At the same time, the enlightenment thinkers in Europe absorbed the spirit of tolerance and atheism in Confucianism, and used it as a weapon of thought against religious theocracy, promoting social reform. They thought China as a state of cultural enrichment, and everyone could read and write. In the Ming and Qing Dynasties, the cultural exchanges between China and Europe have witnessed unprecedented progress, forming the first climax of cultural exchanges between the east and the west. During that time, the Catholic missionaries, especially the Jesuits, served as bridges and bonds. On the one hand, they introduced western scientific and cultural knowledge into China for the purpose of mission, so that the Chinese intelligentsia had a preliminary understanding of western learning. On the other hand, they introduced China's long and splendid culture to Europe by passing letters and translating Chinese classics, and made the "Chinese fever" in Europe, which promoted the enlightenment.

Since the formal establishment of diplomatic relations between China and the EC in 1975, the relationship between China and Europe has made great progress. The two sides have benefited each other through multifaceted and deep cooperation in the past more than 30 years. In October 2003, China and the EU developed a comprehensive strategic partnership, which built a new platform with greater depth and breadth. However, with the changes of the relationship between the US and Europe and functions and strategies of NATO, there were some uncertainties in China-EU relations for the time being. During President Xi Jinping's visit to the EU in 2014, the EU leaders and President Xi agreed to develop partnerships for peace, growth, reform and civilization, pointing the strategic direction for China-EU relations. 2015, marking the 40th anniversary of diplomatic ties, the two sides agreed to enhance synergies between the Belt and Road Initiative and the Investment Plan for Europe, 
and set up the China-EU Joint Investment Fund, and the Connectivity Platform, broadening the new framework of China-EU practical cooperation. From May 31 to June 2 this year, Premier Li Keqiang visited Germany and Belgium, and attended nearly 30 events, enhancing consensus and promoting cooperation. Nowadays, China-EU relations are at their best period in history and are presented with unprecedented historic opportunities of further growth. The Belt and Road Initiative is an important platform of strengthening the mutually beneficial cooperation with the countries relevant, as well as the foundation and tie of the new stage of China -EU cooperation.

How to abandon the uncertainty of China-EU relations and deepen bilateral cooperation so as to pursue mutual benefits are what China and Europe need to focus on in the new era. Both baptized by several wars, China and Europe have the same aspiration for peace. As two important economies in the world, China and Europe should work together to contribute to the recovery of the world economy. The Belt and Road Initiative is a foreign policy based on these strategic considerations. In the spirit of peace, exchange and win-win relationship, this policy will enable the two sides to abandon the uncertainty, and promote common development and mutual benefits, thus providing a powerful impetus for the development of the world.

\section{PROBLEMS AND COUNTERMEASURES OF CHINA-EU} COOPERATION IN THE PERSPECTIVE OF A COMMUNITY WITH A SHARED FUTURE FOR MANKIND

China-EU cooperation is the foundation and bridge of a community with a shared future for mankind. With the development of technology and the progress of transportation industry, the transportation in Eurasia is no longer just a theory. Europe located in the most western Eurasia, China located in the most eastern, only China and Europe carrying out extensive exchange and cooperation, can the entire Eurasian continent truly prosper and develop, which coincides the ancient Silk Road. As the most populous continent with the most countries in the world, Eurasia is carrying the hope of the development of all mankind. At the same time, the effective cooperation and exchange between China and Europe as two major economies has given the world an example. It is also the spiritual connotation advocated by the consciousness of a community with a shared future for mankind, which is achieved through cooperation, and finally widely developed, benefiting the whole world. However, China-EU cooperation still faces some problems and challenges that we need to address.

Firstly, China-EU cooperation faces "institutional problems". China is a socialist country, while the European Union is a capitalist state union, so that the two sides have traditional differences in social system and ideology. Although China-EU relations have made great strides since the end of the Cold War, different from the meaning of "transcending ideology and social system difference" emphasized by China, the EU prefers to export EU values as the precondition, and to make China accept the reforms expected by the EU. Obviously, this is bound to create tension between two sides. From the perspective of a community with a shared future for mankind, China and the EU should foster a new type of international relations, deepen China-EU comprehensive strategic partnership and jointly deal with global problems and challenges. As the largest developing country and the largest group of developed countries, China and Europe should work together to promote the construction of new international relations, renounce discrimination, confrontation and containment, and advocate equality, dialogue and cooperation. In addition, we should respect each other's ideology, social system and values, uphold the spirit of openness and inclusiveness, and achieve innovation and progress in communication. For some time, China-EU high-level exchange and political dialogue have been closer, establishing a comprehensive, multilevel and wide-ranging dialogue and cooperation pattern. The two sides have established more than 70 dialogue mechanisms, from the proliferation of weapons to the security situation in Asia, from the global warming to the fight against illegal migration and trafficking, marking the institutionalization of political cooperation between China and the EU. There is no doubt that the frequent meetings between China and Europe played a leading role. The series of high-level strategic dialogue between the two sides are of great practical significance for the communication and coordination between China-EU relations and major international and regional hot issues of common concern. The two sides also established the inter-party and parliamentary exchange mechanism, and the NPC and the CPPCC formed a regular exchange mechanism with the European Parliament and the European Economic and Social Council. Moreover, since 2010, the annual China-Europe Political Parties Forum has been held. China-EU cooperation, achieving mutual benefits and common development, and delivering benefits to the whole world, validates the "global view" of a community with a shared future which transcends national state and ideology.

Secondly, China-EU cooperation faces "economic problems". The total economy of China and Europe accounts for one-third of the world. Last year, China-EU trade was \$547 billion. The European Union is China's largest trading partner, and China is the EU's second-largest trading partner. However, in recent years, the global economy has slowed down under the influence of the financial crisis, and the conservatism trend has been rising, so that there are some economic and trade frictions between China and Europe. From the perspective of a community with a shared future for mankind, China-EU cooperation should uphold the thinking of common interests. With deep docking between the Belt and Road Initiative, the EU development strategy and the steady progress of China-EU negotiations on the investment agreement, China-EU cooperation have been expanding in the fields of investment and trade. Furthermore, China and Europe also have a wide range of cooperation in technological innovation, energy conservation and emission reduction, capacity cooperation, health services and urbanization. As China and the EU have a high degree of complementarity in economy, trade, industrial structure, science and technology, the cooperation between the two sides is bound to produce a multiplying effect. To deepen China-EU economic cooperation, China and the EU should 
jointly oppose trade protectionism and establish China-EU FTA as soon as possible, which is a major strategic option. China-EU economic cooperation also needs to jointly promote structural reform. The important source of trade protectionism lies in structural contradictions, and the key structural reform is to establish China-EU FTA. China-EU cooperation is also an important link between Asia-Pacific economic circle and European economic circle. With the rapid development and progress of the two economic circles, the economic benefits gained will be shared throughout the world, extending the common interests of all mankind, and confirming the common interest thinking represented by the consciousness of a community with a shared future for mankind.

Thirdly, China-EU cooperation also faces "cultural problems". The image of China in the eyes of the Europeans has been shaped, from Marco Polo's "Kingdom of Gold", to "a closed country" only can be opened by gunboats, from "an authoritarian state" demonized by ideological confrontation during the Cold War, to "a threatening country" publicized by the media hyping up the "Chinese threat theory". How to make the people of the two sides understand each other and how to make the world look at China objectively? This is a difficult but urgent problem to solve. From the perspective of a community with a shared future for mankind, cultural sharing and communication is a good countermeasure. The sharing and exchange of culture help Europe understand China, marking the equality and respect between the two civilizations. At the same time, cultural exchanges, acting on the country and the people, having a profound influence on spirit, can effectively reduce the cognitive gap. The cultural cooperation between China and Europe is not only bilateral, but also multilateral, contributing to the prosperity of world civilization. Through mutual learning and reference, China-EU cultural exchanges show the world how ancient civilizations develop and progress through continuous learning and innovation. In addition, the two sides should also abandon the narrow cultural superiority, focusing on the future at the macro level. In the aspect of multiple nation integration, China has a strong reference to Europe. China and Europe are both multiethnic regions. China has 56 nationalities, but still can maintain stability and harmony, benefiting from its minority policy which takes cultural exchanges as the core. Only through the cultural exchanges, can we deepen the understanding among countries. Moreover, understanding is the premise of trust. Therefore, the cultural exchanges between China and Europe conform to the core connotation of a community with a shared future for mankind, and should be strongly advocated and supported.

\section{CONCLUSION}

At last, China-EU cooperation faces "environmental problems". China is the largest developing country and the world's largest carbon emitter. Because of the development needs, China's annual energy consumption is also huge, so environmental protection is our duty. From the perspective of a community with a shared future for mankind, environmental protection and sustainable development are the obligations of every country. Living in a global village, the environmental problems of any country will affect the environment of this planet. At the same time, the economy and redevelopment of the resources will prolong their lives. In the case of EU-China cooperation, Europe, as the birthplace of the Industrial Revolution, has also experienced the pains of environmental pollution, but the environment in Europe is generally good now. This shows that Europe has sufficient experience and technology in environmental protection. Meanwhile, the Chinese government attaches great importance to environmental protection and tries to solve the contradiction between economic development and environmental protection. The experience and technology of Europe have a great reference and learning significance for China, and also indicate the direction for sustainable development. The environmental cooperation between China and Europe will contribute a lot to the world environment. The two large economies, on the premise of relatively high pollution emissions, focus on environmental protection through bilateral cooperation, making a difference in the world. The cooperation of environmental protection and sustainable development between the two sides is fully in line with the connotation of the consciousness of a community with a shared future for mankind, and also provides an example for all countries to cooperate in building a better earth and protecting their common homeland and interests. To sum up, both China and Europe endeavor to meet the expectation of a better life and promote progress of human civilizations. Although the development path is different, China and Europe are highly correlated in the future. With the deepening of cooperation between China and Europe, the strength and the friendship of the two sides have also been steadily increasing. We believe that the problems can be solved by communication with a shared vision. China-EU relations are at their best period in history and are presented with unprecedented historic opportunities of further growth. The Belt and Road Initiative is an important platform. Through the various, multifaceted and deep cooperation between China and Europe, we will surely be able to bring about a revival of the world economy, bring about a change in the world order, and lay the most solid foundation for creating a harmonious and beautiful earth and a truly free human union.

\section{REFERENCES}

[1] Xi Jinping's Report at the 18th Communist Party of China National Congress, Important literature selection since the 18th CPC National Congress, [M]. Beijing, Central Party Literature Press, 2014.

[2] Chen Xiangyang, Lead the World Order to Reshape with "Community of Human Destiny", [J] The Contemporary World, 2016 (5)

[3] Rao Shiquan, Xi Jinping's Thought of a Community of Shared Future for Mankind and Its Value of the Times, [J]. The Party Building and Ideological Education in Schools, 2016(4)

[4] Zhao Xianjun, The Belt and Road Initiative and Construction of a Community of Shared Future for Mankind, [J]. Journal of Hunan Institute of Socialism, 2016 (1)

[5] Yan Hengyuan, Promote the Further Development of China-EU Comprehensive Strategic Partnership, [N]. China Economic NetEconomic Daily, 2015-05-05 
[6] Ming Hao, The Belt and Road Initiative and a Community of Shared Future for Mankind, [J]. Journal of Minzu University of China, 2015 (6)

[7] Xi Jinping's Speech at Belt and Road Forum for International Cooperation Opening Ceremony, [N/OL].
[N http://cpc.people.com.cn/n1/2017/0514/c64094-29273979.html,

2017-05-14

[8] Wang Tianlong, New Prospects for International Cooperation from the Win-Win Situation between China-EU, N]. Shanghai Securities News, 2015 (7)

[9] Chi Fulin, Deepening China-EU Economic Cooperation and Coping with New Changes in the World, [N]. Shanghai Securities News 2016 (7) 